\title{
Richard Pircher
}

University of Applied Sciences bfi Vienna

Banking and Finance, Austria

E-mail: richard.pircher@fh-vie.ac.at

\section{SELF-LEADERSHIP IN PURPOSE-DRIVEN ORGANIZATIONS: ANALYZING HUMAN PERCEPTION FOR MORE INTEGRATED DECISION- MAKING}

JEL classification: 120

\begin{abstract}
Productive decision-making requires appropriate perception of the facts relevant to the decision. It may be necessary to perceive and integrate diverse and conflicting perspectives appearing inside and outside of the decision-maker. Therefore I scrutinize theoretical and empirical findings on individual human perception as a basis for decision-making and behaviour. Special attention lies on the role of the unconscious (e.g. Bargh, 2006), dual-system approaches (e.g. Kahneman \& Frederick, 2002), self-regulation (e.g. Muraven, Baumeister \& Tice, 1999, Moffitt et al., 2011), and self-leadership (e.g. Manz, 2013). From this foundation I derive guiding self-leadership guidelines for more sustainable internal balancing and more comprehensive integration of external stimuli. Such self-leadership guidelines allow leaders and organizations to identify blind spots more easily and to improve the perception of the inside and the environment. In purpose-driven organizations with distributed authority, the power to decide is distributed among those employees who appear to be competent for the specific topic. Therefore especially within such organizations this self-leadership competency appears to be crucial for success.
\end{abstract}

Key words: leadership, self-leadership, perception, psychology 


\section{INTRODUCTION}

It has been shown that a number of organizations - both profit and nonprofit - show very successful results by applying organizational practices which radically contradict dominating convictions. The US-company Morning Star produces tomatoes worth $\$ 700$ million annually with about 400 employees. They achieve a double-digit growth rate compared to the $1 \%$ of their competitors. The Dutch neighborhood-nursing organization Buurtzorg grew from 10 employees to 7000 with a market share of $75 \%$ within 7 years. These are examples for organizations which differ fundamentally from well-known organizational structures. Among others, three central characteristics of them may be summarized as follows (Hamel, 2011, Laloux, 2014):

To serve the purpose or mission of the organization provides the leading orientation for every decision and action. Whether an idea or argument is good or bad will be judged by this estimation. Every employee at Morning Star for example "is responsible for drawing up a personal mission statement that outlines how he or she will contribute to the company's goal of 'producing tomato products and services which consistently achieve the quality and service expectations of our customers.'” (Hamel, 2011).

The power to take decisions is allocated to those people in the organization who are competent for it. Employees choose how much money to spend on what, even including salaries. They are responsible for acquiring the tools needed to do their work. Employees even define the strategy. There are no titles nor promotions because there is no hierarchy. In such organizations there are no managers anymore. However, everybody is a manager in terms of competencies to decide. One employee puts it like that: "I'm driven by my mission and my commitments, not by a manager.” (Hamel, 2011).

Employees negotiate responsibilities with their peers. They apply market-style practices within their relationships. If they want to make investments larger than what they are able to finance themselves they have to convince colleagues to lend them the rest. "There is a social risk in doing something your colleagues think is stupid.” (Hamel, 2011).

People do not have to fit into predefined boxes. They are expected to take on bigger responsibilities as they develop further competencies. Therefore there are broader and more complicated roles than elsewhere (Hamel, 2011).

It may be concluded that in such organizations the employees have a lot of freedom to do what they are convinced is the best thing to serve the purpose. Simultaneously they have peer-negotiated responsibility for the results of their actions. There are almost no rigid structures like hierarchy and status markers which keep them from fulfilling their mission.

Such a fundamental shift of organizational structure and culture also has its drawbacks. It usually takes a quite long time to get accustomed to it and to get 
productive. Not everybody is willing to enter such an organization or suitable for it. Employees who are used to working in a rigid hierarchical environment may not be able to adjust. This selection criterion is difficult to assess and constitutes a limitation for growth in terms of number of employees. Without a hierarchical ladder to climb, employees may also find it difficult to evaluate and communicate their progress relative to peers. That can become a handicap when they want to switch companies. Peer-negotiated responsibility requires explicit feedback in case a counterpart did not meet his / her promises. This may be challenging for employees on both sides, but it constitutes a core factor for productivity (Hamel, 2011).

It appears to be evident that such a new type of purpose-driven organizations requires people with the ability and willingness to manage their actions and competencies quite independently and to coordinate them with colleagues. On top of their professional expertise they have to establish selfmanagement and self-leadership abilities. Self-leadership may be defined as "a comprehensive self-influence perspective that concerns leading oneself toward performance of naturally motivating tasks as well as managing oneself to do work that must be done but is not naturally motivating” (Manz, 1986: p. 589). In addition to self-management, the concepts of the "what" and "why" are covered. Through the focus on the "why" and "what" of self-influence, individual selfleaders address the underlying reasons for effort and behavior (Manz, 2013). Increased self-leadership corresponds with better affective responses and improved work performance (Stewart, Courtright \& Manz, 2011).

In the following sections of the paper I will analyze the relevance of human perception to self-leadership and derive adequate guidelines for employees. Conclusions for purpose-driven organizations will be drawn.

\section{PERCEPTION}

"All you have is what you notice"

Roshi Baker

Perception is the main basis for learning and behavior. For us as human beings our abilities to perceive the environment and our own bodies with our senses are very limited in quantity and quality. For instance we are not able to perceive magnetic and electric fields like some birds and fish, UV light and carbon dioxide like bees and ultrasound like bats (Chittka \& Brockmann, 2005).

Perceiving starts with input signals from the senses which are handled in a cascade of cortical brain regions (bottom-up). This flow appears to be in a constant interaction with feedback from the brain facilitation (top-down). The brain first uses rudimentary signals to derive analogies, linking that input with representations in memory. Therefore we may understand perception as a mutual activity of bottom-up and top-down processes. The latter seems to build upon 
expectations of the most likely interpretations of the input image. The top-down process facilitates recognition by substantially limiting the relevant object representations. This provides focused predictions which facilitate perception and cognition (Bar, 2007). Recognition thus rather resembles an iterative approximation than an exact matching process. It builds upon what is already known.

Limitations of our senses like the blind spot in our eyes where the nerves leave the eyeball are automatically corrected by the brain. We do not see anything missing or unusual at this point. "We do not see that we do not see" (von Foerster, 2003, p. 284).

To focus on something means overlooking almost everything else. An experiment shows that even a highly salient human in a black gorilla suit walking through a scene showing off beating her breast may be invisible for viewers for this reason (Most, Scholl, Cliffort \& Simons, 2001). Also substantial changes in images are not recognized under certain circumstances by many observers, which is an effect known as change blindness. Change blindness seems to be very counterintuitive because most people firmly believe that they would notice such large changes - a kind of "change blindness blindness" (Simons \& Rensink, 2005, p. 17).

We may conclude that human perception is very limited in quantity and quality, highly subjective, iterative and approximate. It is strongly influenced by our internal patterns which consist of both a legacy of evolution and a product of personal history. The limitations of our perception are easily overlooked. We do not see what we do not see.

\section{AUTOMATICITY AND CONSCIOUSNESS}

"The intuitive mind is a sacred gift and the rational mind is a faithful servant. We have created a society that honors the servant and has forgotten the gift."

Albert Einstein

People who recalled an experience of social exclusion, experience a lower room temperature than others who recalled an inclusion experience (Zhong, Chen-Bo, \& Leonardelli, 2008). Watching pictures of items drawn from business contexts (e.g. briefcases, boardroom tables, fountain pens, etc.) leads to a more competitive behavior than watching pictures of neutral objects like cups (Kay, Wheeler, Bargh \& Ross, 2004). These are just a few examples of very many studies where the so-called priming effect takes place in a statistically significant way: A stimulus unconsciously and automatically triggers the response to a later stimulus. It is suggested that these effects increase with the degree of ambiguity 
(Kay et al., 2004). Hence priming seems to be an unconscious solution to fill the disturbing gap of uncertainty.

Human decision-making was found to be distorted from rationality in many ways (e.g. Ariely, 2008). One example of many is myopia, the tendency to search for immediate gratification and to fail in long-term planning (e.g. Hardin \& Looney, 2012). Even if people know that biases may occur in human judgment, they tend to unconsciously ignore the possibility to be biased themselves (Pronin, Olivola \& Kennedy, 2008). Regarding business plans, it was found that there is a cognitive bias to accentuate the positive aspects, which is called planning fallacy (Lovallo \& Kahneman, 2003). Thus there are many indications that we tend to favor everything which attunes us in a positive mood and flatters our ego: seemingly immaculate perception, unbiased judgment, very promising business plans, etc.

These examples show that unconscious mental processes exhibit a strong distortive influence on behavior and decision-making. However, it is very efficient and fast to process inputs automatically. Daily activities like driving a car mainly rely on automatic and unconscious processes which are believed to have high capacity and to be fast and independent of the central working memory (e.g. Evans, 2008). Novice golfers for example perform more poorly under time pressure whereas skilled golfers even benefit from reduced performance time (Beilock, Bertenthal, Hoerger, \& Carr, 2008). Automatized, unconscious processes allow us to rapidly and holistically interpret our environment, to process these interpretations and to act.

Unconscious effects "are ubiquitous and pervasive across the major forms of psychological phenomena: appraisal and evaluation, motivation and goal pursuit, social perception and judgment, and social behavior. This research has been impressive in demonstrating the wide scope and reach of nonconsciously instigated influences on our daily lives” (Bargh, 2006, p. 148). They even dominate behavior according to results of empirical research: "Everyday intuitions suggest full conscious control of behavior, but evidence of unconscious causation and automaticity has sustained the contrary view that conscious thought has little or no impact on behavior. [...] conscious causation is often indirect and delayed, and it depends on interplay with unconscious processes” (Baumeister, Masicampo, \& Vohs, 2011, p. 331).

Consciousness was not necessary for the survival of life as such. This ability probably appeared very late during the evolution of life. Nevertheless it seems to be the key factor for at least many of the successes of mankind: It allows us to integrate behavior across time. It enables us to benefit from past events for present and future events. Furthermore, consciousness introduces social and cultural factors. Conscious thought helps us to deal with multiple alternatives and conflicting possibilities (Baumeister, et al., 2011). Another powerful aspect of consciousness is self-awareness, which means becoming the object of one's own attention. To have self-awareness and to be able to experience your own mental states is a logical basis for making inferences 
about other people's states of mind. The theory of mind signifies "the cognitive capacity to attribute mental states to self and others” (Goldman, 2012, p. 402).

We may conclude that the unconscious inevitably influences our awareness without being noticed. It offers fast, comprehensive and powerful processing but is not directly manageable. Consciousness and self-awareness first of all allow us to identify inconsistencies within ourselves and with the external context. "[M]ost and possibly all human behavior emerges from a combination of conscious and unconscious processes" (Baumeister, et al. 2011, p. 354).

\title{
4. HOMEOSTASIS AND SELF-REGULATION
}

"Between stimulus and response there is a space. In that space is our power to choose our response. In our response lies our growth and our freedom."

Viktor E. Frankl

An organism has to maintain more or less stable internal conditions despite a changing external environment. The self-regulating process which "maintain[s] stability while adjusting to changing conditions" (Billman, 2013, p. 159 ) is called homeostasis. Regarding physiology, e.g. blood pressure, breath, etc., this is an unconscious automatic process.

Humans may achieve the ability to regulate themselves mentally as well. Self-control and self-regulation are crucial for a person's ability to deal with emotions. They include the ability to alter one's own responses, e.g. to inhibit emotions, to modify one's thoughts, feelings and behaviors. There is strong empirical support for the assumption that these capabilities play an important role for the whole life. "Insofar as self-regulation liberates human behavior from being driven solely by external stimuli and automatic, reflexive, or instinctual responses, it contributes greatly to the diversity and flexibility of human behavior.” (Muraven, Baumeister \& Tice, 1999, p. 446). The presence of these abilities in childhood correlates with attributes like high socio-economic status, good health and a low percentage of criminal incidents and pathology as adults. People who manage to acquire these abilities during their life-times still may profit from the positive effects (e.g. Moffitt et al., 2011).

\section{USING THE BEST OF BOTH WORLDS}

\author{
"To play a symphony \\ you have to tune your instruments. "
}

Ivar Vehler

Summing up we may say that unconscious and conscious processes exhibit characteristics which represent strengths and weaknesses relevant to 
specific contexts and objectives. Unconscious, intuitive mental processes are automatic, effortless, associative, rapid and parallel and result in skilled action. Consciousness by contrast is controlled, effortful, deductive, slow, serial, selfaware and results in rule application (Kahneman \& Frederick, 2002).

Being aware of the strengths and weaknesses of the conscious and the unconscious allows us to consciously integrate them into real life and to activate them appropriately (e.g. Nordgren, Bos \& Dijksterhuis, 2011). Some examples are given in the following.

It is a truism that you should think before doing something. However, in most day-to-day cases we do not. Usually we just act automatically like we are used to, e.g. when brushing our teeth or driving a car. If something unexpected arises like toothache or surprising roadworks, we have to stop automaticity and start to think about what to do. We tend to use consciousness as rarely as possible due to its demand in energy and the limited capacity of our working memory.

We know that thinking has its merits, but thinking too much can result in drawbacks. It potentially reduces preference consistency (Nordgren et al., 2011) and decision satisfaction (Ariely \& Norton, 2011), e.g. decisions that would provoke arguments lead to favoring other decisions which are easy to explain to others but are not consistent with our own feelings and preferences anymore.

Another very common aspect of thinking too much is to address too many attributes and options. Basically, an increase in available information improves decision accuracy but not infinitely. In the case of a mismatch between the amount of information input and the cognitive abilities we may call it a situation of information overload. If someone has to handle too much information, accuracy decreases (see figure 1, Eppler \& Mengis, 2004, p. 326).

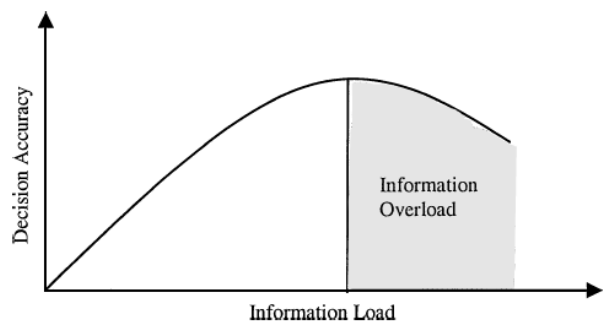

Figure 1. Information Overload

Focusing perception is obviously necessary for analyzing, planning, etc. Otherwise, focusing leaves out a lot of the context which could be important. Thus non-focusing may also be advantageous. Mind-wandering for example has positive effects like making diverse perspectives visible and fostering creativity (Schooler, Mrazek, Franklin, Baird, Mooneyham, Zedelius, \& Broadway 2014). Automatic, spontaneous associations build upon unconscious resources. They offer a potential source for new perspectives and alternative approaches. 
The concept of 'sleeping over a problem' is more than just a manner of speaking. During sleep, when consciousness and focus are mainly deactivated, memory is reprocessed which appears to be an important factor for how our memories are formed and ultimately shaped (e.g. Stickgold, 2005). Sleep shapes internal structures and helps to process contents unconsciously.

For both individual and collective intentions it may be concluded that “... the decision maker might be wise to ask both questions - `Am I thinking too much? Am I thinking too little?” (Ariely \& Norton, 2011, p. 44).

\section{DEIDENTIFICATION}

$$
\begin{array}{r}
\text { "What happens when people are ... } \\
\text { over-attached to their creation and ideas?... } \\
\text { What is my new role in life?" }
\end{array}
$$

Dan Ariely

It appears to be logical that not only planning for the future and learning from the past are crucial for private life and leadership. Also being able to become aware of the present moment is important. To perceive what is actually going on in an open-minded, comprehensive and multidimensional manner (facts, emotions, desires, fantasies, weak signals, intuitions, etc.) means detaching oneself at least partially from what has been taken for granted up to now. The abilities to be patient and to tolerate ambiguity, frustration and anxiety are not only required to identify a good point of time for action but also to avoid bustling and to send signals of calmness and firmness to other people and colleagues (Simpson \& French, 2006). Practices like individual self-dialogue and mental imagery may increase mental performance, show positive effects like enthusiasm, job satisfaction, and self-efficacy, and decrease negative affects like nervousness (Neck \& Manz, 1996). It is also found that methods to foster mindfulness and contemplation may change brain and immune functions in a positive way. By applying them it appears to be possible to enhance a sense of equanimity and clarity, and increase empathy and relational satisfaction (Kabat-Zinn, 2003; Siegel 2007).

Summing up, we may say that detachment and deidentification from present convictions and expectations releases perception for what is actually out there. It releases awareness of something unknown up to now. This potentially could even open a door for the self to develop further (e.g. Graves, 1966; Loevinger, 1997; Cook-Greuter, 2000; Beck \& Cowan, 1996; Cowan \& Todorovic, 2000; Rooke \& Torbert, 2005). To watch earth from outer space proved to be an eye opener for some astronauts as well as for observers watching it on TV. This was called the big picture or overview effect (White, 1998). Thereby individual minds tune into a global context. 


\section{ORIENTATION FOR SELF-LEADERSHIP}

“A lasting, committed daily practice is the only way to produce sustained transformation."

Wilber / Patten / Leonard / Morelli 2012

Based on the arguments demonstrated above, the following points for orientation show - like light-houses - the direction towards more connected and integrated self-regulation, perception and behavior. I propose these guiding principles to support internal and external balancing and to improve adaptability:

Foster self-perception and self-awareness: Train the ability to mentally step outside of yourself and to become aware of inner feelings, desires, memories, tensions, weak signals, intuitions, etc. Comprehensive self-awareness is required to become the leader of yourself. Become aware of and appreciate your personal (or organizational) "instruction manual”, the unique characteristics of your internal structures: What are your strengths and weaknesses? How did your history lead to the current status? What are you able to appreciate? What is "just" a result of history? What do you want to change? How do you perceive your own body? Does it tell you something? What are your core topics and core purposes?

Avoid data overflow, and search for blind spots: Keep your capacity for information-processing in mind, reduce noise that is data which cannot be processed anymore and confuses instead of improving orientation. Reflect the impact of quantity and quality of external stimuli on your internal state.

Invite conflicting perceptions and perspectives, guide your ways in unusual directions every now and then, try to appreciate contradiction and to examine paradoxes instead of denying them. Open yourself up for detours and for getting touched by something unknown. Connect yourself to the bigger picture.

Shape your internal structures, train self-regulation, find your personal ways for internal balancing and regeneration: Usually we do what we are used to. Therefore it is important to take care of what we get used to. Design your habits consciously. Establish your ability to consciously deal with emotions, deliberation, desires, memories, fantasies, weak signals, intuitions, etc. Maybe you decide to let them naturally flow or to direct them in order to prevent damage. Self-regulation is a precondition to avoid troublesome and devastating decisions and irreversible damage. Find your ways to come back to an appropriate level of internal tension somewhere between burden and floppiness.

Consciously invite your unconscious, the powerful automatic resources: Create space for both focus and mind-wandering, for closed and open modes, try to articulate and integrate suppressed perspectives, provide space for weak signals, for perceptions of pressure and contradiction, for dreams and 
spontaneous associations, use sleep for unconscious processing, leave open spaces, enjoy the silence.

Integrate analysis and contemplation: Complexity may be approached in two ways: first to divide it into pieces analytically and second to dissolve the ego in it without words. The first one is easily traceable and communicable. The latter allows for taking advantage of much more diverse, comprehensive, yet implicit, subjective and unconscious resources within oneself and collectives than the explicit, analytical one. Individual experiences during contemplation can partly be made explicit, individually and collectively.

Aim at appropriate modesty based on limited human resources on the one hand and almost unlimited complexity on the other: As human perception and its processing are very restricted in relation to the complexity of the world, our ability to understand and control even a small fraction of the environment will always be extremely limited and iteratively influenced by developments elsewhere. The impact of narrow-minded actions may be shattering.

Aim at appropriate courage based on resonance of the inside and the outside: Explore the unknown possibilities mindfully. Listen carefully whether self-perception and perception of the surrounding field resonate with each other. Listen to your inner voice and accept it as one instrument of an orchestra. There are memories, rationality, emotions, desires, phantasies and weak, unique signals from the depth. Train to distinguish those various voices. These multifaceted voices are not reality, they are not the truth, they are what they are. Accept this orchestra as it is: If it does not communicate at all, if it communicates in a gentle or vague manner, if it is very clear and strong and does not leave you in any doubt.

Aim at detachment and deidentification from existing internal structures: "Yes, that's the way how I (we) act at the moment ... Yes, that's the way how I (we) decide at the moment ... Yes, that's what I (we) believe at the moment. All this is not me (us). What I (we) am (are) at the moment does not limit myself (ourselves). What I (we) am (are) right now does not restrict what I (we) will become to be right afterwards or in weeks, months, years, decades.”

Step into and continue your personal way to connect yourself practically to the bigger picture and support the evolvement of life as such, e.g. through interaction with the younger or elder generation or in nature.

\section{CONCLUSIONS}

In this article some selected findings on human perception and cognition are briefly depicted. On this basis guiding principles for individual behavior were derived. They are applicable to day-to-day life and promise to reduce unproductive and devastating ways of homeostasis. To follow these guidelines allows more comprehensive integration of internal and external stimuli and 
fosters more sustainable decision-making and behavior. If trained and automatized in practice, they appear to increase the adaptability of individuals, teams and organizations.

In purpose-driven organizations with distributed authority essentially any employee fulfills management tasks. Therefore it may be found advisable for such organizations to support their employees in the development self-leadership competencies. They seem to be essential for the execution of their professional role. The employees have need for the competency to perceive stimuli around and within themselves and to integrate them into their behavior and decision-making. Additionally in such organizations the lack of status markers and the focus on participation could be challenging for newcomers. To be able to deal with a need for self-affirmation and with the desires of the own ego could also be crucial. The development of self-leadership capacities could make it easier for new employees to get accustomed to a fundamentally different organizational culture. in 2015

Further reading: the author will publish a book on the topic of this paper

\section{REFERENCES}

Ariely, D. (2008), Predictably Irrational. Harper Collins, New York.

Ariely, D. \& Norton, M. I. (2011), From thinking too little to thinking too much: a continuum of decision making, Cognitive Science, Vol.2, No.1, p. 39-46.

Bar, M. (2007), The proactive brain: using analogies and associations to generate predictions, Trends in cognitive sciences, Vol.11, No.7, p. 280-289.

Bargh, J. A. (2006), What have we been priming all these years? On the development, mechanisms, and ecology of nonconscious social behavior, European journal of social psychology, Vol.36, No.2, p.147-168.

Baumeister, R. F., Masicampo, E. J., \& Vohs, K. D. (2011), Do conscious thoughts cause behavior? Annual review of psychology, No.62, p. 331-361.

Beilock, S. L., Bertenthal, B. I., Hoerger, M., \& Carr, T. H. (2008), When does haste make waste? Speed-accuracy tradeoff, skill level, and the tools of the trade, Journal of Experimental Psychology Applied, Vol.14, No.4, p. 340-352.

Beck, D. E., \& Cowan, C. C. (1996), Spiral Dynamics Spiral Dynamics - Mastering Values, Leadership, and Change. Blackwell, Malden.

Billman, G. E. (2013), Homeostasis: the dynamic self-regulatory process that maintains health and buffers against disease. In Sturmberg, J. P., Martin, C. M. (Ed.), Handbook of Systems and Complexity in Health (p. 159-170). Springer, New York.

Chittka, L., Brockmann, A. (2005), Perception space - the final frontier, PLoS biology, Vol.3, No.4, p. 0564-0568.

Cook-Greuter, S. R. (2000), Mature ego development: a gateway to ego transcendence?, Journal of Adult Development, Vol.7, No.4, p. 227-240.

Cowan, C. C., Todorovic, N. (2000), Spiral dynamics - the layers of human values in strategy, Strategy \& Leadership, Vol.28, No.1, pp.4-12 
Eppler, M. J., Mengis, J. (2004), The concept of information overload: A review of literature from organization science, accounting, marketing, MIS, and related disciplines, The information society, Vol.20, No.5, p. 325-344.

Evans, J. St. B. T. (2008), Dual-processing accounts of reasoning, judgment, and social cognition, Annu. Rev. Psychology, Vol. 59, p. 255-278.

Goldman, A. I. (2012), Theory of mind. In Margolis, E., Samuels, R., Stich, S. (Ed.), Oxford Handbook of Philosophy and Cognitive Science (p. 402-424). Oxford University Press, Oxford.

Graves, C. W., (1966), “The Deterioration of Work Standards”, in: Harvard Business Review, Vol.44, No.5, S.117-126

Hamel, G. (2011). First, Let's Fire All the Managers, Harvard Business Review, Dec. 2011, https://hbr.org/2011/12/first-lets-fire-all-the-managers [accessed 5.5.2015]

Hardin, A. M., Looney, C. A. (2012), Myopic loss aversion: Demystifying the key factors influencing decision problem framing. Organizational Behavior and Human Decision Processes, Vol.117, No.2, p. 311-331.

Kabat-Zinn, J. (2003), Mindfulness-based interventions in context: past, present, and future, Clinical psychology: Science and practice, Vol.10, No.2, p. 144-156.

Kahneman, D., Frederick, S. (2002), Representativeness revisited: Attribute substitution in intuitive judgment. In Gilovich, T., Griffin, D., Kahneman, D. (Eds): Heuristics of Intuitive Judgment: Extensions and Applications. Cambridge University Press, New York.

Kay, A. C., Wheeler, S. C., Bargh, J. A., Ross, L. (2004). Material priming: The influence of mundane physical objects on situational construal and competitive behavioral choice. Organizational Behavior and Human Decision Processes, 95(1), 83-96.

Laloux, Frederic (2014): Reinventing Organizations: A Guide to Creating Organizations Inspired by the Next Stage of Human Consciousness, Brussels: Nelson Parker

Loevinger, J. (1997), Stages of Personality Development. In Hogan, R., Johnson, J., Briggs, S. (Eds.), Handbook of Personality Psychology (p. 199 - 208). Academic Press, San Diego.

Lovallo, D., Kahneman D. (2003), Delusions of Success: How Optimism Undermines Executives’ Decisions. Harvard Business Review, Vol.81, No.7, p. 56-63.

Manz, C. (1986), Self-leadership: Toward an expanded theory of self-influence processes in organizations. Academy of Management Review 11.3. p. 585-600.

Manz, C. (2013), Taking the Self-Leadership High Road: Smooth Surface or Pot Holes Ahead?. The Academy of Management Perspectives, Dec. 2014

Merry, P. (2009), Evolutionary Leadership. Integral Leadership for an increasingly complex world. Integral Publishers, Pacific Grove

Moffitt, T. E., Arseneault, L., Belsky, D., Dickson, N., Hancox, R. J., Harrington, H., ... \& Caspi, A. (2011). A gradient of childhood self-control predicts health, wealth, and public safety. Proceedings of the National Academy of Sciences, Vol. 108, No.7, p. 2693-2698.

Most, S. B., Scholl, B. J., Clifford, E. R., \& Simons, D. J. (2005), What you see is what you set: sustained inattentional blindness and the capture of awareness, 
Psychological review, Vol.112, No.1, p. 217-242. Selective attention test: https://www.youtube.com/watch?v=vJG698U2Mvo (Nov. 27, 2014), The monkey business illusion: https://www.youtube.com/watch?v=IGQmdoK_ZfY (Nov. 27, 2014)

Muraven, M., Baumeister, R. F. , Tice, D. M. (1999), Longitudinal improvement of self-regulation through practice: Building self-control strength through repeated exercise, The Journal of social psychology, Vol.139, No.4, p. 446-457.

Neck, C. P., Manz, C. C. (1996), Thought self-leadership: The impact of mental strategies training on employee cognition, behavior, and affect, Journal of Organizational Behavior, p. 190-203

Nordgren, L. F., Bos, M. W., Dijksterhuis, A. (2011), The best of both worlds: Integrating conscious and unconscious thought best solves complex decisions, Journal of Experimental Social Psychology, Vol.47, No.2, p. 509-511.

Pronin, E., Olivola, C. Y., Kennedy, K. A. (2008), Doing unto future selves as you would do unto others: Psychological distance and decision making, Personality and Social Psychology Bulletin, Vol.34, No.2, p. 224-236.

Rooke, D., Torbert, W. R. (2005), 7 Transformations of Leadership, Harvard Business Review, April 2005, p. 67-76

Schooler, J. W., Mrazek, M. D., Franklin, M. S., Baird, B., Mooneyham, B. W., Zedelius, C., Broadway, J. M. (2014), The Middle Way: Finding the Balance between Mindfulness and Mind-Wandering, Psychology of Learning and Motivation, Vol.60, No.60, p.1-33.

Siegel, D. J. (2007), Mindfulness training and neural integration: differentiation of distinct streams of awareness and the cultivation of well-being, Social Cognitive and Affective Neuroscience, Vol.2, No.4, p. 259-263.

Simons, D. J., Rensink, R. A. (2005), Change blindness: Past, present, and future, Trends in Cognitive Sciences, Vol.9, No.5, p. 16-20

Simpson, P., French, R. (2006), Negative capability and the capacity to think in the present moment: Some implications for leadership practice, Leadership, Vol.2, No.2, p.245-255.

Stewart, G. L., Courtright S. H., and Manz, C. (2011), Self-leadership: A multilevel review." Journal of Management 37.1, p. 185-222.

Stickgold, R. (2005), Sleep-dependent memory consolidation, Nature, Vol.437, p.1272-1278

von Foerster, H. (2003), On Constructing a Reality. In von Foerster, H., In Understanding understanding (p. 211-227). Springer, New York.

White, F. (1998), The Overview Effect: Space Exploration and Human Evolution, Second Edition. AIAA, Reston. Overview effect: https://www.youtube.com/watch?v=CHMIfOecrlo (Nov. 27, 2014)

Zhong, C., Leonardelli, G. J. (2008), Cold and Lonely Does Social Exclusion Literally Feel Cold?, Psychological Science, Vol.19, No.9, p. 838-842. 